\title{
A triple negative breast cancer: what it is not!
}

\author{
This article was published in the following Dove Press journal: \\ Breast Cancer:Targets and Therapy \\ 23 February 2012 \\ Number of times this article has been viewed
}

\section{Suresh B Katakkar \\ Regional Medical Oncology Hematology Leader, Centre for the North, BC Cancer Agency, Prince George, British Columbia, Canada}

Correspondence: Suresh B Katakkar BCCA - Centre for the North, I475 Edmonton St, Prince George BC V2M IS2, Canada Tel: + I 2505652535

Fax: + I 2505652500

Email suresh.katakkar@northernhealth.ca
Abstract: The triple negative cancer is an unusual, and at the same time, a unique entity where the discordance rate is almost $18 \%$. That means $18 \%$ of Her 2 negative results will transform into a Her2 positive status and will have the affinity to spread to the central nervous system (CNS). With the identification of CD44, CD24, and ALDH1, we may be able to determine which group of triple negative breast cancer patients will have CNS metastasis. This case illustrates the Her2 expressing cells have higher CNS affinity. As the original tumor was Her2 negative, if a genomic assay was then done on this patient, we would have identified the potential of CNS involvement. In conclusion, genomic assays should be routinely done on triple negative cancers.

Keywords: triple negative, breast cancer, claudin high or low, genomic microassay

\section{Introduction}

With this case illustration, we want to show how a triple negative breast cancer is not what it appears to be. The triple negative breast cancer is a unique entity that has been shown to be basal. ${ }^{1,2}$ This is definitely not one disease; genomic and microarray assays have shown this to be inhomogeneous cancer. Though we could not perform the genomic assay, had it been done we believe we could have shown in this patient CD44 high, CD24 low, and ALDH1 high expressing cells.

\section{Case history}

Our patient was in triple negative stage II and treated with anthracycline- and taxanebased chemotherapy, but when it metastasized, it showed Her2 positive cancer cells in the CNS location and triple negative features in the lung metastasis. This is the first reported human case that such discordance between primary and metastatic disease is shown.

A 43-year-old female patient was diagnosed with infiltrating ductal carcinoma of the left breast. She underwent a left modified radical mastectomy at Mayo Clinic in Scottsdale, AZ. Her carcinoma was triple negative and was 1.5 centimeters in size with two axillary lymph nodes showing metastasis. She then had adjuvant chemotherapy with epirubicin and docetaxel $75 \mathrm{mg} / \mathrm{m}^{2}$ intravenously, every 3 weeks for six sessions. She required granulocyte colony-stimulating factor support from the second session onwards, as she developed febrile neutropenia following the first chemotherapy treatment.

Two years later, whilst in remission, she had a bilateral reconstruction following simple mastectomy on the right side. In the third year, as she was visiting her family in Puerto Rico, she developed severe headaches followed by seizures. The computed tomography $(\mathrm{CT})$ 
scan showed singular CNS metastasis. After stabilization, she was transferred to Tucson, Arizona, to the author's care. There, a magnetic resonance imaging (MRI) of the head confirmed singular metastasis in the left frontal lobe. The patient had no localizing signs. The CT scan of the abdomen, chest, and pelvis showed right hilar metastasis. The central nervous system (CNS) metastasis was completely resected and showed Her2 positive and hormone receptor negative cancer. She received CNS radiation and FILM ${ }^{3}$ chemotherapy along with trastuzumab. After three sessions, she had a repeated MRI of the head and a CT scan of the chest, abdomen, and pelvis. She was in complete remission. She received three additional sessions of chemotherapy and continued trastuzumab for 1 year.

Three months later, she had an MRI of the head which showed she had no recurrence; however, a positron emission tomography (PET) CT scan showed recurrence of a right hilar mass, but no evidence of any other metastasis. She was then started on capecitabine and trastuzumab. After 3 months, a repeat PET CT scan showed partial response and an MRI of the head was still negative for recurrence. She had good performance status, therefore a mini thoracotomy was done and the right hilar mass was completely removed. To our surprise, this mass was triple negative like the primary. She then received three additional sessions of capecitabine and trastuzumab was withheld.

Four months later, she had right upper quadrant pain and a PET CT scan showed liver metastasis and recurrence of a right hilar mass. At this stage, her performance status was poor; hence, she was introduced to hospice services. She passed away three weeks later.

\section{Discussion}

This case illustrates the inhomogeneous feature of triple negative breast cancers and the difficulty in treating them. With the advent of new research in genomic and microarray assay, we believe that we can identify groups of patients with a higher potential of CNS metastasis.

It is well known that triple negative breast cancers have poor prognoses. Almost one third of them have CNS metastasis. ${ }^{4}$ The triple negative breast cancers are basal and recent genomic and microarray studies have shown it to be very heterogeneous. Prat and $\mathrm{Perou}^{5}$ have shown it to be claudin high or low. In addition, further genomic analysis has shown that some of the basal types are CD44 high, CD24 low, and ALDH1 high, whereas some are CD44 low, CD24 high, ${ }^{6}$ and ALDH1 low. ${ }^{7,8}$ It is the former type that has shown to have a predisposition for CNS involvement. The discordance rate in triple negative breast cancers has been shown to be $17.6 \%$. That means $17.6 \%$ of triple negative breast cancers transform to Her2 positive status. Brufsky et $\mathrm{al}^{4}$ have shown that almost $33 \%$ of Her 2 positive breast cancers have had CNS metastasis.

Triple negative breast cancers have also shown increased vascularity on MRI scans of the breast, ${ }^{6,9}$ indicating increased angiogenesis. Does this mean they secrete an increased amount of vascular endothelial growth factor and, if so, should we incorporate angiogenesis inhibitor routinely with chemotherapy in these patients?

Even though the Food and Drug Administration has retracted approval of angiogenesis inhibitors in breast cancers, there may be an indication for it in the triple negative breast cancers. As bevacizumab is used in glioblastoma multiforme, there may be a need for it in CD44 high, CD24 low, and ALDH1 high expressing tumors which have high CNS affinity.

\section{Conclusion}

As the molecular analyses shed more light on triple negative breast cancer, we think it will become the norm to do these analyses on this unique type of cancer. This will be the major molecular determinant to lead to the individualization of care for this cancer.

\section{Disclosure}

The author reports no conflicts of interest in this work.

\section{References}

1. Gaedcke J, Traub F, Milde S, et al. Predominance of the basal type and Her-2/neu type in brain metastasis from breast cancer. Mod Pathol. 2007;20(8):864-870.

2. Lehmann BD, Bauer JA, Chen X, et al. Identification of human triple-negative breast cancer subtypes and preclinical models for selection of targeted therapies. J Clin Invest. 2011;121(7):2750-2767.

3. Davidson NG, Davis AS, Woods J, Snooks S, Cheverton PD. FILM(5Fluorouracil, Ifosfamide, Leucovorin and Mitomycin C), an alternative chemotherapy regimen suitable for the treatment of advanced breast cancer in the 'out-patient' setting. Cancer Chemother Pharmacol. 1999;44 Suppl:S18-S23.

4. Brufsky AM, Mayer M, Rugo HS, et al. Central Nervous system metastases in patients with Her2 positive metastatic breast cancer: incidence, treatment, and survival in patients from registHER. Clin Cancer Res. 2011;17(14):4834-4843.

5. Prat A, Perou CM. Deconstructing the molecular portraits of breast cancer. Mol Oncol. 2011;5(1):5-23.

6. Disease characterization of triple negative breast carcinomas using functional MRI Abstract 2112 ECCO 15 Vol. and No. 2.

7. Nakshatri H, Srour EF, Badve S. Breast cancer stem cells and intrinsic sub types: controversies rage on. Curr Stem Cell Res Ther. 2009;4(1):50-60.

8. Croker AK, Allan AL. Inhibition of aldehyde dehydrogenase (ALDH) activity reduces chemotherapy and radiation therapy resistance of stemlike ALDH(hi)CD44(+) human breast cancer cells. Breast Cancer Res Treat. 2011. [Epub ahead of print.]

9. Nalwoga H, Arnes JB, Stefansson IM, Wabinga H, Foulkes WD, Akslen LA. Vascular proliferation is increased in basal-like breast cancer. Breast Cancer Res Treat. 2011;130(3):1063-1071. 


\section{Publish your work in this journal}

Breast Cancer: Targets and Therapy is an international, peer- View the full aims and scopes of this journal here. The manuscript reviewed open access journal focusing on breast cancer research, management system is completely online and includes a very quick identification of therapeutic targets and the optimal use of preven- and fair peer-review system, which is all easy to use. Visit http:// tative and integrated treatment interventions to achieve improved www.dovepress.com/testimonials.php to read real quotes from outcomes, enhanced survival and quality of life for the cancer patient. published authors.

Submit your manuscript here: http://www.dovepress.com/breast-cancer---targets-and-therapy-journal 